\title{
Application of Agent-Based Model Simulation for Tsunami Evacuation in Pacitan, Indonesia
}

\author{
Fadly Usman ${ }^{1, *}$, Keisuke Murakami ${ }^{2}$, Agus Dwi Wicaksono ${ }^{1}$, and Eko Setiawan ${ }^{3}$ \\ ${ }^{1}$ Department of Urban and Regional Planning, Faculty of Engineering, University of Brawijaya, \\ Malang, Indonesia \\ ${ }^{2}$ Department of Civil and Environmental Engineering, University of Miyazaki, 1-1 Gakuen Kibanadai \\ Nishi, Miyazaki 889-2192, Japan \\ ${ }^{3}$ Faculty of Computer Science, University of Brawijaya, Malang, Indonesia
}

\begin{abstract}
The most significant measure in reducing tsunami disaster is an early evacuation. The aim of this study is to developments a dynamic evacuation model with using simulation of Agent-Based Modeling and Simulation (ABMS). The Shelter Plan Analysis is also conducted in this study to establish applicable evacuation places. All analysis in this study based on a geographic information system (GIS) data such as shelter location, evacuation networks, housing and other information. The shelter plan analysis is the methods to evaluate an applicable shelter. The important variable in this analysis is nearest accessibility based on the existing road from the residential area to the evacuation building. In order to set input data for this analysis, we conducted a questionnaire survey to the local people in Pacitan, which is a typical populated coastal city in Indonesia, located in East Java province. The agent-based model is according to multi criteria decision making (MCDM) for internal and external factor. The concept of MCDM was used to develop a weighted suitability decision matrix in a simulation's model. We also conducted the field survey in this city, especially focused on the condition of evacuation shelters and evacuation networks, in order to evaluate the shelter plan on GIS as well as to conduct the simulation of the agent-based model.
\end{abstract}

\section{Introduction}

This paper describes the development of an application of agent-based model simulation for tsunami evacuation in Pacitan City, Indonesia. Evacuation is a common strategy for handling emergency situations. Evacuation is a process in which threatened people displaced from dangerous areas to evacuation places, in order to reduce the health and life vulnerability of affected people. During disaster response, evacuation should be conducted accurately, and in a hurry.

As a result, preparation, testing and training of a proper evacuation plan required as a part of disaster preparedness. However, evacuation planning is a complex problem involving many behavioral and management facets (M. Saadatseresht et al. 2009). Sherali

*Corresponding author: fadlypwk@ub.ac.id, fadlypwkftub@gmai.com 
et al. (1991) studied the evacuation plan for natural disaster such as hurricanes and floods with explicit consideration of the impact of shelter locations on evacuation time. Cova and Justin (2003) presented a network flow model for identifying optimal lane-based evacuation routing plans in a complex road network. A mixed-integer programming solver used to derive routing plans for sample networks. Pursals and Garzon (2009) considered the building evacuation problem and developed a model for selecting the proper routes for movement of people into a building during an emergency situation.

Mansourian et al. (2006) studied that most of the data required for emergency management and evacuation planning have a spatial component or location that represents a significant opportunity to utilize geographical information systems (GIS). Pal et al. (2003) have discussed the development of a traffic simulation methodology on GIS and spatial data, which could be used for emergency evacuation planning purposes. This methodology seeks to give optimal evacuation alternatives in the most efficient routes for evacuation of the population from the affected region. Mansourian et al. (2006) used spatial data infrastructure (SDI) concepts and Web-based GIS to facilitate disaster management. They used Web-based GIS to facilitate spatial data sharing among disaster management parties for better planning and decision-making.

ElDessouki (1998) had presented that to develop an evacuation plan. It is necessary to determine safe areas. Another significant job is involved determining the distribution of evacuees into the safe areas. Each evacuee understood where should they go and from which route. $\mathrm{Wu}$ and Zhang (2006) added to achieve a proper plan for evacuation places, a planner should consider the capacities of the safe areas and the distance to the safe areas as two main factors during the planning. In other words, in an evacuation plan, the distribution of evacuees into the safe areas should be based on the capacity of the safe areas. And at the same time, each evacuee should go to the nearest safe area. M. Saadatseresht et al. (2009) considered Multi Objective Evolutionary Algorithms (MOEA) and the geographical information system (GIS) for evacuation planning. In his study, he proposed a three-step approach the safe areas, is a spatial Multi Objective Optimization Problem (MOP), because the objective functions and data required for solving the problem has a spatial component.

The advantages of agent-based approach are capture emergent phenomena, provides a natural environment for the study of certain systems, and flexible, particularly in relation to the development of geospatial models (Andrew T. Crooks and Alison J. Heppenstall, 2012). The agent-based modeling approaches the complex system into individual component as an agent. Agent-Based Model and Simulation (ABMS) are a computational method and system, to understand the interacting agent behavior in an artificial environment (Sutikno and Murakami, 2011). The potential role of GIS in evacuation planning was explained by a number of studies. More specifically, there are few studies integrating GIS and multi objective techniques for evacuation planning (Balram and Dragicevic, 2006). For the problem of this research intends to present utilization of Multi Criteria Decision Making (MCDM) techniques and GIS as integrated frameworks for evacuation planning.

We added a consideration of household behavior into evacuation modeling in this study. The model developed on Repast Simphony toolkits, which can be used for early and the nearest network during evacuations processed. Both of analysis based on geographic information system (GIS) data such as shelter location, evacuation networks, housing, agent and other information. This system consists of two parts; (1) the modeling for the street, shelter and agents using geographical information system data in ArcGIS, and (2) analysis of disaster evacuation using agent-based model simulation. Furthermore, it is possible to investigate the appropriate evacuation route by the simulation. 


\section{Literature Review}

Tsuji et al. (1995) reported that the last historical tsunami caused by the earthquake in Java Island, and it arrived the coast about 50 minutes after the main shock. The epicenter of this earthquake is different from the supposed earthquakes by Mardiatno et al. (2008) We estimate tsunami traveling time to Pacitan as approximately 21 minutes based on the shallow-water theory. Mardiatno et al. (2008) conducted tsunami inundation simulation on coastal area in Pacitan. For determining tsunami inundation area, we supposed possible maximum earthquake in this area as magnitude 8.0 from historical data. Located at the south coast of Java, Pacitan is facing a seismic gap between two tsunami-earthquake events, which are the 1994 (M 7.2) and the 2006 tsunami (M 7.7). (A. Muhari et al, 2012). The location of its hypothetic epicentre is $111.0^{\circ} \mathrm{E}$ and $-9.5^{\circ} \mathrm{S}$. Angle parameters are strike $(\theta)$ $276^{\circ}$, dip $(\delta) 10^{\circ}$ and slip $(\lambda) 95^{\circ}$. The other source parameters are length $120 \mathrm{~km}$, width $60.1 \mathrm{~km}$, depth $10 \mathrm{~km}$ and dislocation $5.20 \mathrm{~m}$. We conducted the field survey to get the spatial information of houses, household and settlement by using a digital camera with GPS, which used to specify the location on the Geographic Information Systems (GIS). This survey conducted to collect data about the street condition such as the width of street, pavement type, and level of service (LOS). LOS in this study is used to analyze the street condition by measuring traffic flow with number of vehicles and corresponding safe driving conditions. The local government of Pacitan City (BAPPEDA Pacitan, 2002) designated 44 evacuation shelters in case of a tsunami disaster as shown in Fig. 1.

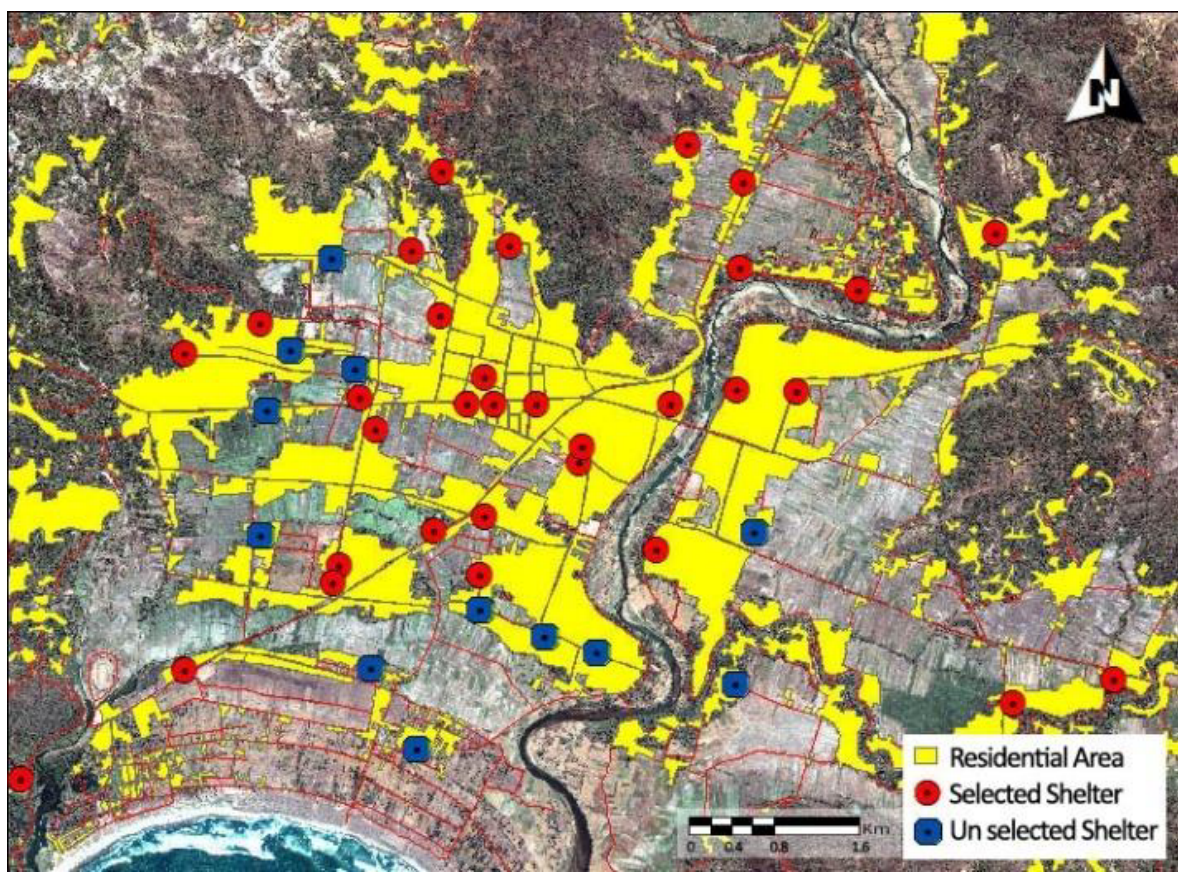

Fig. 1. Selected and unselected shelter.

It is assumed that around $5.4 \mathrm{~km} 2$ of the total of $10.8 \mathrm{~km} 2$ of residential areas in Pacitan City were inundated, and around $76 \%$ of them were inundated by water that was more than $1 \mathrm{~m}$ deep as seen on Fig. 2. These results occurred because the residential areas are located mainly on the low-land area in Pacitan City. 
Most of the evacuation shelters designated by the local government are the open-space areas located in the hilly terrain. Based on field survey and weighting analysis, this study found that 12 shelters (blue colour in Fig. 1) cannot be used as temporary evacuation places for several reasons. The main reason of unselected shelter is the poor of building quality and limited of building capacity (Usman and Murakami, 2011).

The distribution of selected and unselected shelter after scoring is shown on Fig. 1 which 32 facilities as temporal shelter shown in red-coloured dots. Based on several criteria such as nearest with inundated area and coverage of service area to the vulnerable area, 16 building facilities were selected as temporal shelter in this study (Fig 2).



Fig. 2. Shelter and inundated area.

This study was identified the location of mosques in Pacitan city as temporary evacuation places. Mosque is usually designed with specific criteria such as unique roof, simple shape and large capacity. Through field check, also found some public buildings such as hospitals, schools, hotels and government offices that can be supposed as the temporary evacuation place. Residential areas for this study include areas where there are houses, government offices, schools, shop-houses, market buildings, and other public facilities.

This study is organized two parts of analysis; the first part is an analysis by using the shelter coverage area which called Shelter Plan Analysis. The objective of this analysis is to identify the service area of the shelters based on the longest distance and limitation of evacuate time. In this study, evacuate time are grouped into two distances. Distance of $900 \mathrm{~m}$ for 15 minutes of evacuates time, and the longest mileage is $1200 \mathrm{~m}$ for 20 minutes of evacuates time. We set the average of walking speed is $1.0 \mathrm{~m} / \mathrm{s}$. The second part is an analysis by using Agent-Based Modeling and Simulation (ABMS). The objective of this part is to get the best routes in evacuation. The variables in ABMS are evacuee, street, and shelter. 


\section{Shelter plan analysis}

Mardiatno et al. (2008) estimated that most of the residential areas in Pacitan city are inundated by the tsunami due to this supposed earthquake. The inundation areas more than $0.5 \mathrm{~m}$ depth spread to landward deeply as shown in Fig. 4. With considering above tsunami traveling time, this study set tsunami evacuation time as 15 and 20 minutes in order to investigate the maximum area that residents could evacuate to their shelters within the limitation of evacuation time. Fifteen-minute evacuation means an urgent situation that could be happened under the delay of evacuation warning.

Evacuation with vehicle sometimes causes a traffic jam, and it could disturb safety evacuation of others (Sutikno et al., 2011). This study supposes the evacuation by foot under tsunami evacuation. The walking speed defers depending on the physical condition of an evacuee such as age, sex, topographic condition, network condition and others. This study assumes that all residents evacuate with walking speed between $1.0-1.5 \mathrm{~m} / \mathrm{sec}$.

Evacuation speed of $1.0 \mathrm{~meter} / \mathrm{sec}$ is speed of a dependent elderly during an evacuation and evacuation speed of $1.5 \mathrm{~meter} / \mathrm{sec}$ is used as the average speed of the person together with a child during tsunami evacuation (Potangaroa, 2008). In this study, we choose the slowest of evacuation speed $(1.0 \mathrm{~m} / \mathrm{sec})$ to analyze the applicable shelter in the Pacitan city, using Network Analyst extension by ArcGIS. We are conducted two cases in shelter plan analysis; Case-1 consists of 11 shelters, where five shelters were not included in simulating according to an assessment of the evacuation building in the previous study (Usman and Murakami, 2011). Table 1 shows scoring of six-teen shelters in Fig. 2. And Case-2 in this study consists of 16 shelters which located on inundated area as seen on Fig 2.

Table 1. Scoring list of the Shelter.

\begin{tabular}{|c|c|c|c|c|c|c|c|c|}
\hline \multirow{2}{*}{ No } & \multirow{2}{*}{ Name } & \multirow{2}{*}{$\begin{array}{c}\text { Building } \\
\text { Level }\end{array}$} & \multirow{2}{*}{$\begin{array}{c}\text { Floor Area } \\
\text { (m2) }\end{array}$} & \multirow{2}{*}{$\begin{array}{c}\text { Floor and } \\
\text { Land Area (m2) }\end{array}$} & \multicolumn{3}{|c|}{ Scoring } & \multirow{2}{*}{ Score } \\
\hline & & & & & Distance & Capacity & Construction & \\
\hline 1 & Masjid Al Muhajirin Perumnas & 1 & 225 & 1600 & 3 & 2 & 3 & 8 \\
\hline 3 & Masjid Kel Sidoharjo & 1 & 180 & 1091 & 2 & 2 & 1 & 5 \\
\hline 4 & Masjid Ds Sirnoboyo & 1 & 110 & 160 & 3 & 1 & 1 & 5 \\
\hline 5 & SMK Bina Karya & 2 & 1700 & 5112 & 3 & 3 & 2 & 8 \\
\hline 8 & Masjid Al Muhajirin & 1 & 230 & 550 & 2 & 1 & 2 & 5 \\
\hline 9 & Masjid Perumnas & 1 & 250 & 850 & 3 & 1 & 1 & 5 \\
\hline 10 & Masjid Pompes Al anwar & 2 & 540 & 1400 & 3 & 2 & 2 & 7 \\
\hline 11 & STKIP PGRI & 2 & 700 & 2902 & 3 & 2 & 2 & 7 \\
\hline 12 & SDN Ploso 1 & 2 & 520 & 980 & 3 & 2 & 2 & 7 \\
\hline 16 & SMK1 Pacitan & 2 & 2400 & 6700 & 3 & 3 & 2 & 8 \\
\hline
\end{tabular}

Fig. 3 shows the distributions of service area, which is defined as the maximum area in which residents can evacuate to the nearest shelter within each evacuation time. The service areas on each evacuation times are drowned in different colors. Table 2 shows the percentage of covered area and number of covered people in Pacitan city under the available condition of all allocated shelters and evacuation networks. As shown in Fig. 3, some areas are uncovered even in the case of 20 minutes of evacuation time. 


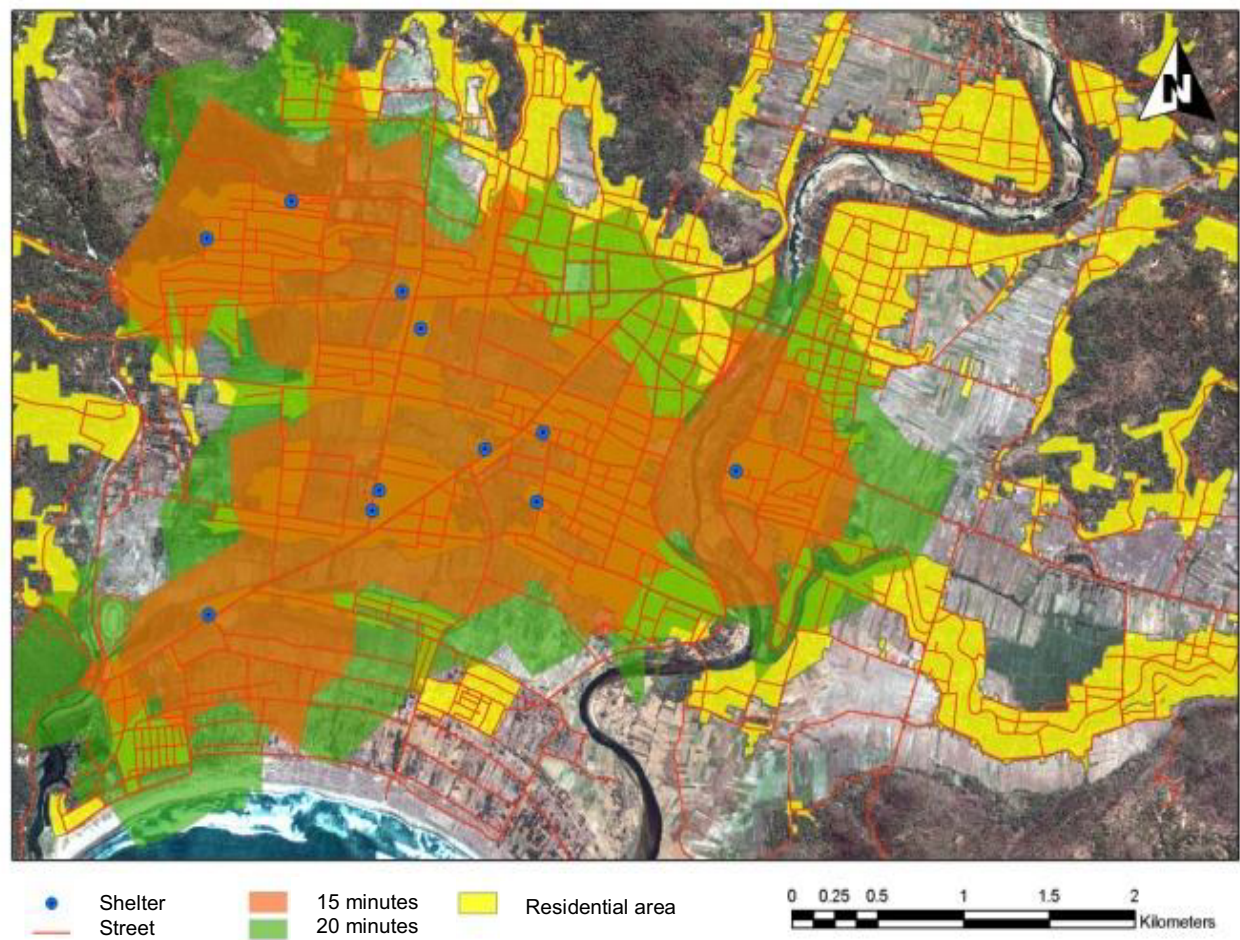

Fig. 3. Service area of Case-1 with 11 shelters.

With decreasing of evacuation time, covered area becomes smaller. In the case of 15 minutes of evacuation, which seems an urgent situation due to some troubles in the earlywarning transmission system, only less than a half of residential area could be covered by current shelter allocation in case- 1 . About $73 \%$ of the residential area is covered by 11 shelters allocation in 20 minutes of evacuation. And only $61 \%$ of the residential area is covered in 15 minutes of evacuation time even in the new shelter allocation (Table 2).

Table 2. Percentage of coverage area in Case-1.

\begin{tabular}{|c|c|c|c|c|c|}
\hline \multirow{2}{*}{$\begin{array}{c}\text { Evacuate } \\
\text { Time }\end{array}$} & \multicolumn{3}{|c|}{ Coverage } & \multicolumn{2}{c|}{ Non coverage } \\
\cline { 2 - 6 } & Area & People & Percentage & Area & Percentage \\
\hline $15 \mathrm{mt}$ & 8.12 & 48,192 & $84.87 \%$ & 1.45 & $15.13 \%$ \\
\hline $20 \mathrm{mt}$ & 9.21 & 54,661 & $96.26 \%$ & 0.36 & $3.74 \%$ \\
\hline
\end{tabular}

This result shows that need more allocation shelter to cover all of service area for people evacuation. We use all of shelters in the vulnerable area in Case-2. These facilities which eliminated before could be used as a temporal shelter by improving structure quality and recommend expanding the capacity of shelter. Fig. 4 shows the service areas in Case- 2 .

In comparison with Fig. 3, the increase of the service areas can be observed in beach side and rural area in each evacuation time. Table 3 shows the percentage of the covered area in each village. About $96 \%$ of the residential area is covered by 16 shelters allocation in 20 minutes. On the other hand, only $84 \%$ of the residential area is covered in 15 minutes of evacuation time as shown on Table 3. 


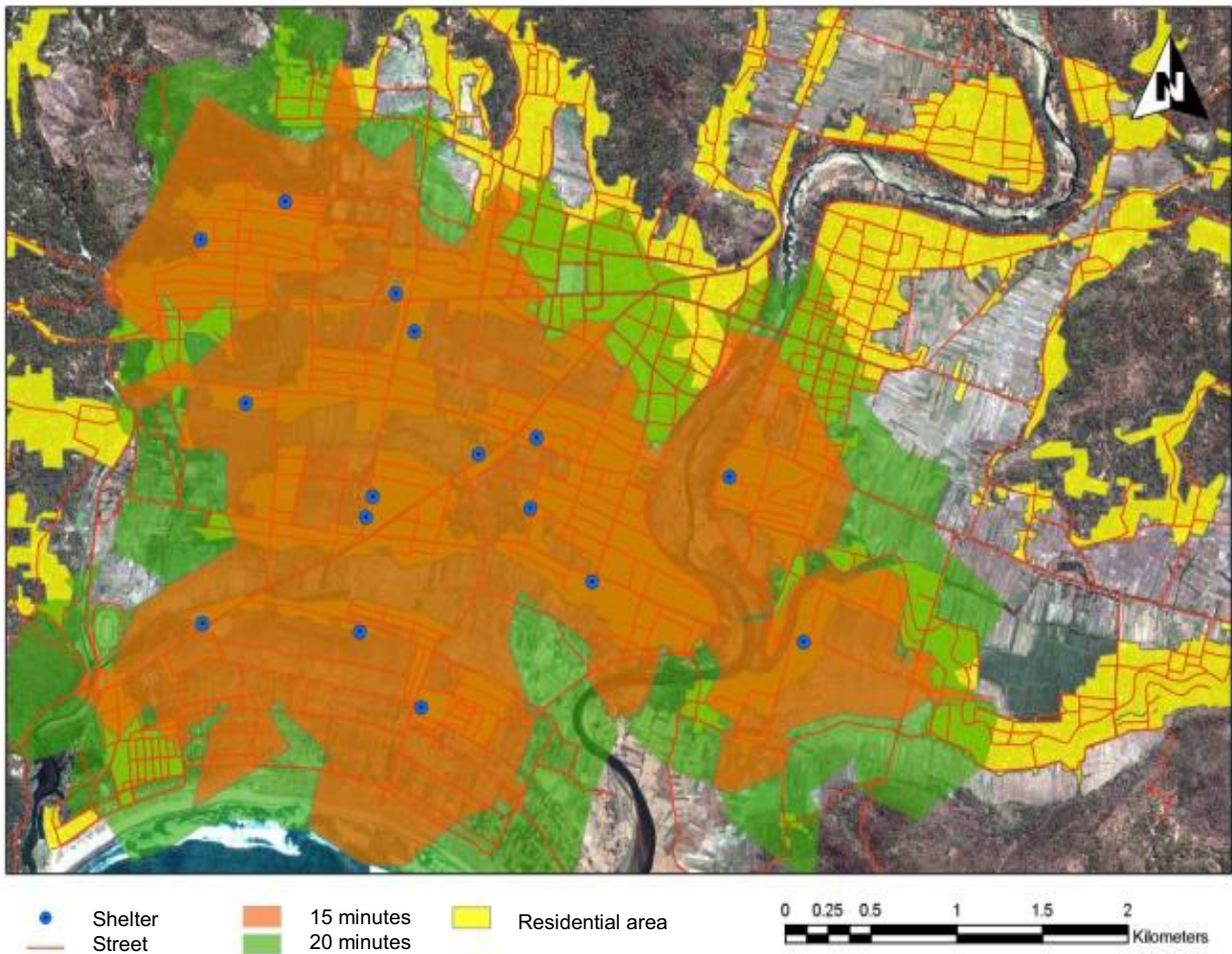

Fig. 4. Service area of Case-2 with 16 shelters.

Table 3. Percentage of coverage area in Case- 2 .

\begin{tabular}{|c|c|c|c|c|c|}
\hline \multirow{2}{*}{$\begin{array}{c}\text { Evacuate } \\
\text { Time }\end{array}$} & \multicolumn{3}{|c|}{ Coverage } & \multicolumn{2}{c|}{ Non coverage } \\
\cline { 2 - 6 } & Area & People & Percentage & Area & Percentage \\
\hline $15 \mathrm{mt}$ & 8.12 & 48,192 & $84.87 \%$ & 1.45 & $15.13 \%$ \\
\hline $20 \mathrm{mt}$ & 9.21 & 54,661 & $96.26 \%$ & 0.36 & $3.74 \%$ \\
\hline
\end{tabular}

\section{Agent based model and simulation}

The objective of agent-based model simulation is to verify the results that obtained through the Shelter Plan Analysis. In the analysis before, parameters of analysis are the nearest distance to determine coverage of service area. In the agent-based model, simulations carried out several approaches designed as closely as possible to the real condition and situation. This study is modifying the Agent-Based Model and Simulation (ABMS) of virtual city from RepasCity model, in order to develop agent-based for tsunami evacuation. The source codes of the models are developed by using Repast Simphony toolkit. Repast Simphony is designed to provide visual and tools for agent model design, agent behavior specification, model execution and result examination (North and Macal, 2007). Repast has multiple implementations in several program language and built-in adaptive features such as algorithm and regression. Repast is an open-source, cross platform, agent-based modeling and simulation toolkit.

In making a decision, an agent has their own condition called Internal Factors (IF). In this study, the Internal Factor of the agent is age that related to the speed of evacuation; 
such width, street quality, and slope. All agents will choose a network based on the ability of each agent. Fig. 5 under is shown Multi Criteria Decision Making (MCDM) diagram for Internal Factor (IF) and External Factor (EF) in Agent-Based Model and Simulation. The movement of an agent is having unique condition and other variables that govern the movements of agents are street quality and building capacity as the External Factor in simulation. For example, a 60 years-old agent will choose the wide, flat, and smooth street. While other 20 years-old agents would like to choose any street as long as the paths are nearest to the shelter.

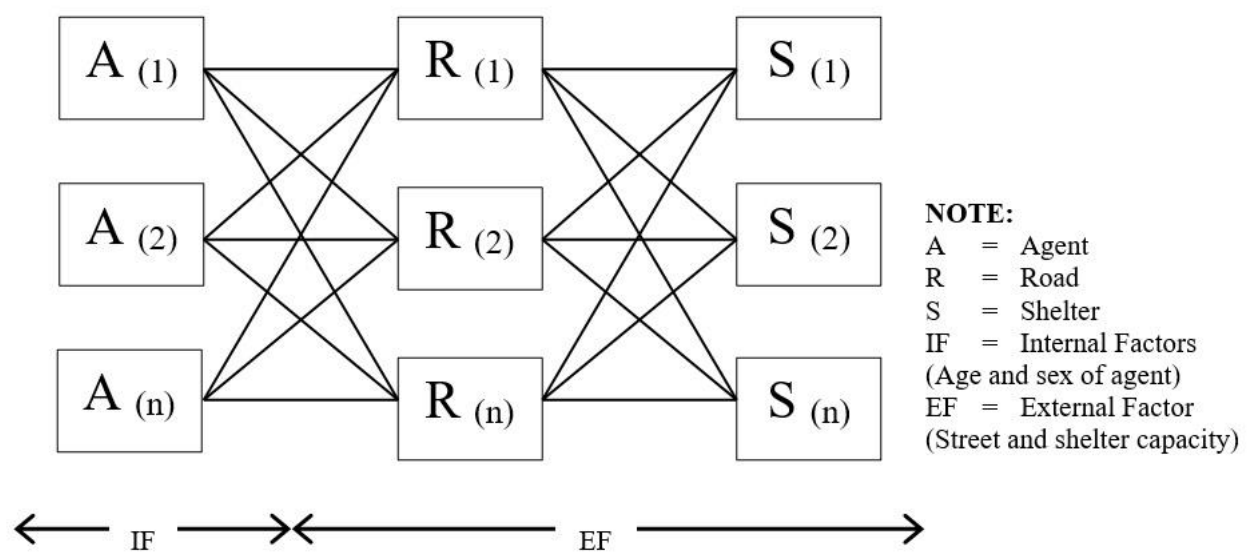

Fig. 5. Multi criteria hierarchy for agent-based model.

The development of tsunami evacuation consists three parts: construct context and projection, build environment, and define agent movement behaviour. A context is used to store a population of agent. Projection is used to define the relationship between each agent. Without any projection, agent would not be able to interact with each other (Sutikno and Murakami, 2011). Environment component in this simulation such as houses, shelter, road and junction layer are used to build an artificial environment of the model. Location data and properties of road network, shelter, building and agents are stored in GIS files, and then the agent behaviour is implemented as an algorithm in Java. The agent movement behaviour is defined to give agent's response to their environment when tsunami warning is announced. In this study is assumed that the individual households are treated as a selfsupporting unit to making decision on the road to traffic environment and to the evacuation building. Evacuation modelling is a complex process, which is supposed to include many factors.

Table 4. List of scenario in agent based model and simulation.

\begin{tabular}{|c|c|c|c|c|}
\hline No & Scenario & Shelter & Shelter Capacity & Building Collapse \\
\hline 1 & Scenario-1 & 11 & No & No \\
\hline 2 & Scenario-2 & 16 & No & No \\
\hline 3 & Scenario-3 & 16 & Yes & No \\
\hline 4 & Scenario-4 & 16 & Yes & Yes \\
\hline
\end{tabular}

In order to simply the model, this study assumes that the evacuees have to move to the nearest shelter without considering the capacity of shelter for Scenario-1 and 2. In Scenario- 
choose different shelter, that nearest with evacuation shelter before. This study is divided speed of agent into 2 categories, elder $(1.0 \mathrm{~m} / \mathrm{sec})$, and young person $(1.5 \mathrm{~m} / \mathrm{sec})$ and number of agents in this simulation is 425 agents which representing 4 villages and 8,000 residents. In Scenario-4, we conduct a case with building collapse variable. In this scenario, the material of building collapse blocked network and cause some evacuee cannot escape from vulnerable area to the shelter. Table 4 shows the list of scenario conducted in this study.

\subsection{Scenario 1}

In Pacitan city, the local governments officially provide several shelters that could be used to place refugee in the case of the tsunami as shows on Fig. 1. This study is only evaluating the tsunami evacuation plans in prone residential base on inundated area as seen on Fig. 2. This study assumes that the evacuees are households that live in the vulnerable area. Their initial position is the center of their houses, and they start to evacuate from their house to the shelter after announcement. All of data are prepared by using ArcGIS toolkit in shape file data format. Fig. 6 shows location of 11 shelter and agents at initial condition.

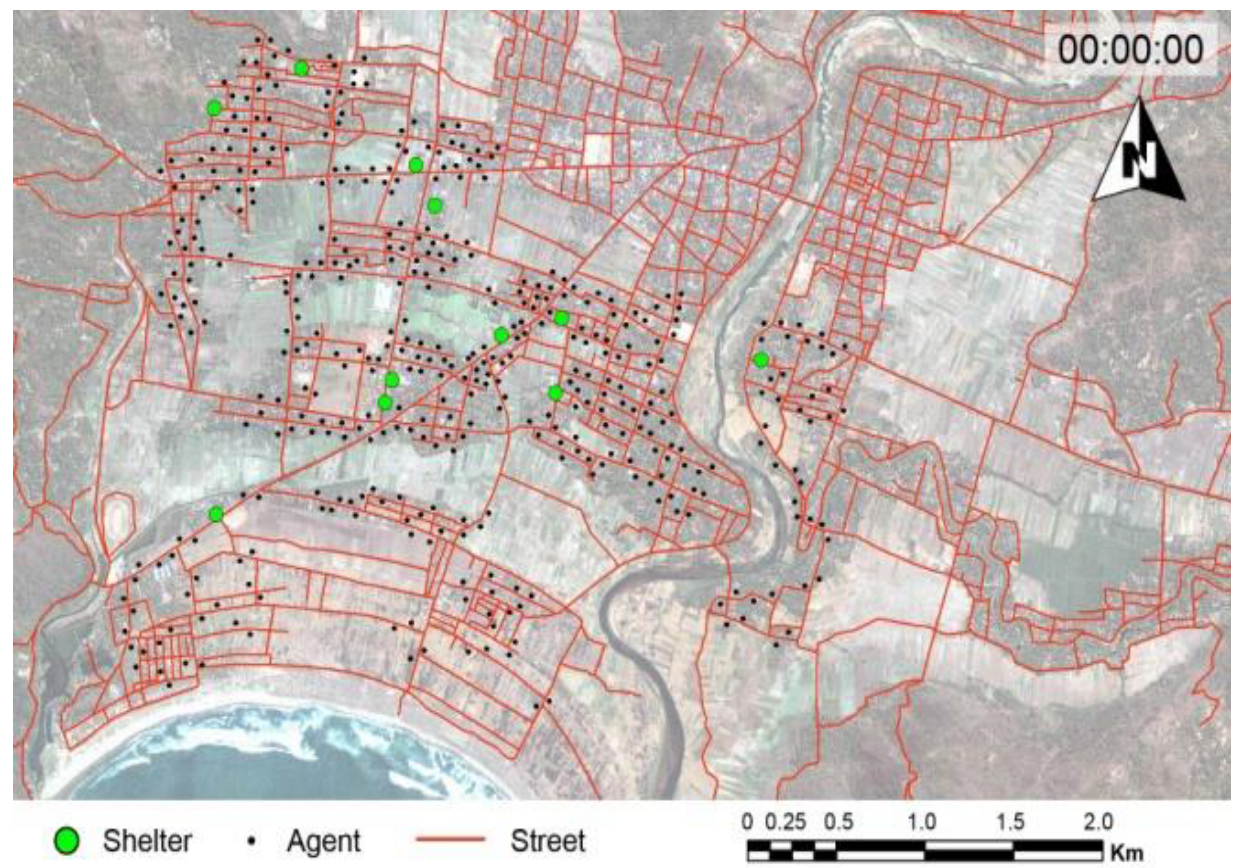

Fig. 6. Shelter and agents at initial condition in Scenario-1.

In Scenario-1, evacuation time is 27 minutes to evacuate all agents to the shelters. It is a long evacuation time because the required time for evacuation is about 15 minutes after the announcement of tsunami warning. Therefore, other scenarios were conducted to get better condition and faster than scenario-1 by add several shelters, which allocated at prone residential area. 


\subsection{Scenario 2}

As the results obtained in the previous analysis in Shelter Plan Analysis, 11 evacuation places are not enough in the service area of building coverage and longer time of evacuation in Agent-Based Model and Simulation. In Scenario-2, simulation contains all shelter as seen in Fig. 2. The result in Agent-Based Model Simulation has similarities with the evaluation of Shelter Plan Analysis. In Shelter Plan Analysis, we found that coverage of the service area was increased significantly up to $96 \%$ in 20 minutes, and in the AgentBased Model and Simulation, evacuate time is about 13.5 minutes only.
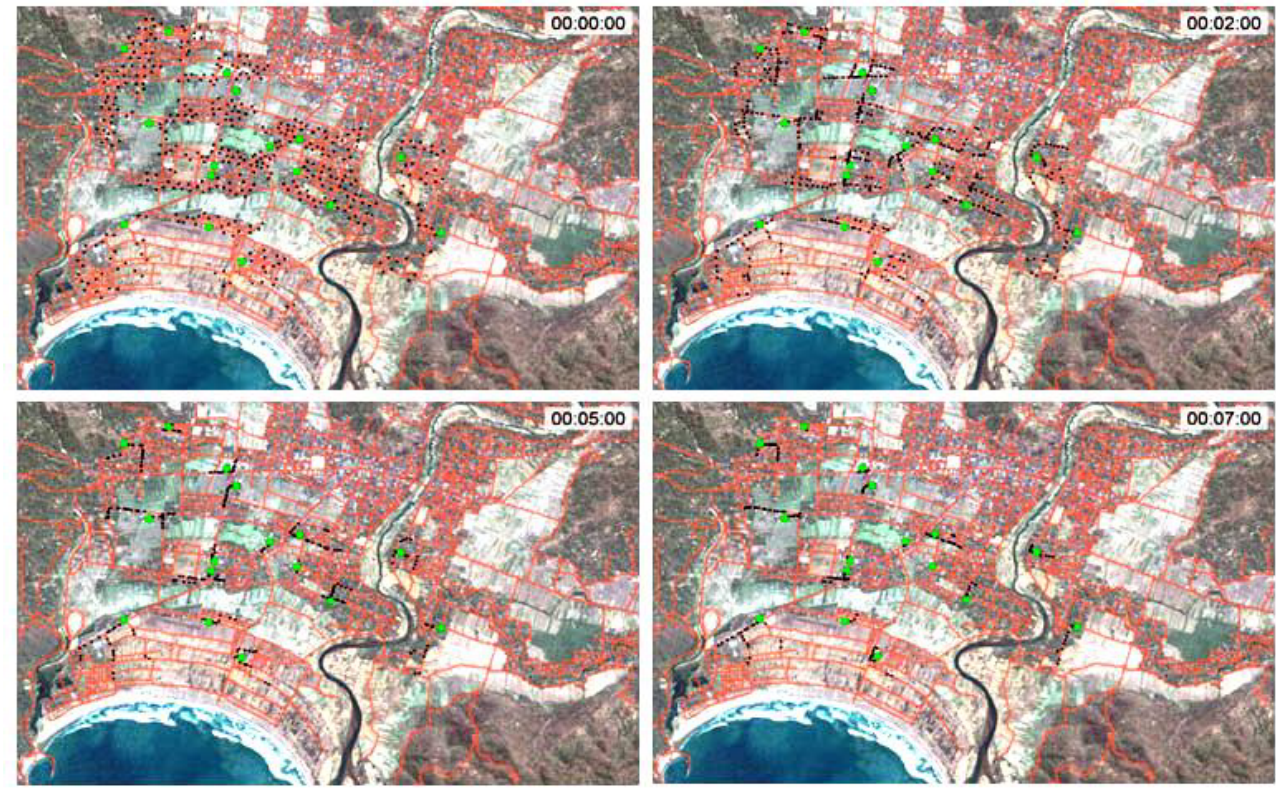

Fig. 7. Movement of agent at initial condition ( 0 minute), 2, 5 and 7 minutes in scenario-2.

In Scenario-2, evacuation time is 13.5 minutes which faster than Scenario-1 in evacuate all agents to the shelter. It is a better time to evacuate, because the required time for evacuation is about 15 minutes after the announcement of tsunami warning. Scenario-1 and 2 have not included the variable of building capacity. If the capacity of shelter is exceeded, agents require additional time to choose another nearby shelter. Fig. 7 shows movement of agent at initial condition, 2, 5 and 7 minutes.

\subsection{Scenario 3}

The behavior of agents will change when we conducted a parameter of building capacity. In Scenario-3, evacuation time is 19.5 minutes to evacuate all agents to the shelters. It is danger time to evacuate because the required time for evacuation is about 15 minutes after evacuee heard the announcement of tsunami warning. However, at the minute 13.5, agents have been evacuated to the shelter about $92 \%$, that means only $8 \%$ need longer time to evacuate because exceeds the ability of the building capacity.

In Scenario-3, some agents move to another shelter after capacity of the nearest shelter was full. Fig. 8 shows that some agents move from shelter 10 to 9 , from shelter 12 to 11 and from 14 to 13 . Table 5 shows total agents, equivalent to the number of people, 


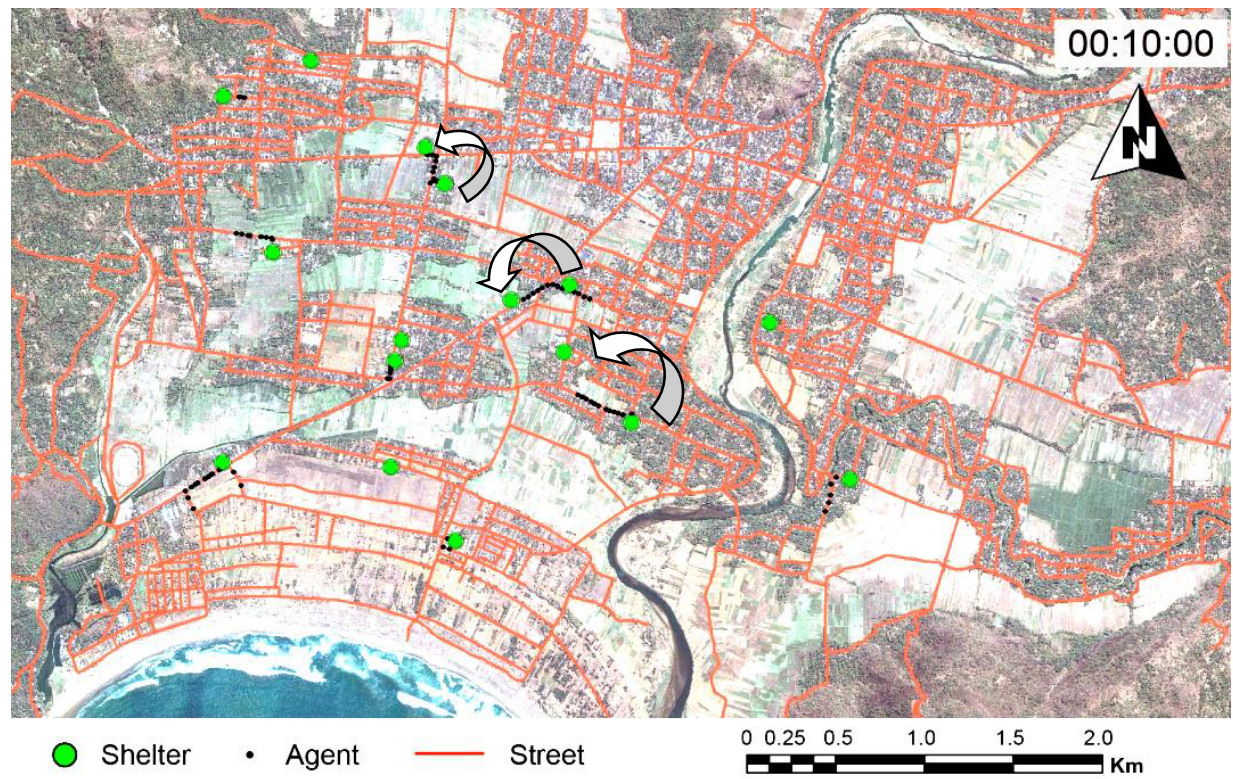

Fig. 8. Agents movement after 10 minutes in Scenario-3.

Table 5 shows that one agent representing twenty residents, so twenty agents representing about four hundred people. In Scenario-3 Shelter 10, 12 and 14 was filled full by the agent after 6 minutes, and other agent move to the nearest shelter from the previous shelter. This action requires a longer travel time for residents to reach the nearest shelter. Based on the phenomenon of agent movement in Scenario-3, a recommendation to the government is to increase the capacity of the evacuation building. This effort can be done to shorten the travel time.

Table 5. Total agents, building capacity and evacuate times.

\begin{tabular}{|c|c|c|c|c|c|c|}
\hline \multirow{2}{*}{ No } & Total & Equivalent & Building & Percentage & Evacuate & Evacuate \\
\hline & Agent & to the people & Capacity & (\%) & Time 1 & Time 2 \\
\hline 1 & 26 & 520 & 800 & $65.0 \%$ & 14 & 0 \\
\hline 2 & 20 & 400 & 600 & $66.7 \%$ & 10 & 0 \\
\hline 3 & 28 & 560 & 600 & $93.3 \%$ & 12 & 0 \\
\hline 4 & 36 & 720 & 800 & $90.0 \%$ & 14 & 0 \\
\hline 5 & 22 & 440 & 500 & $88.0 \%$ & 8 & 0 \\
\hline 6 & 30 & 600 & 750 & $80.0 \%$ & 13 & 0 \\
\hline 7 & 26 & 520 & 600 & $86.7 \%$ & 11 & 0 \\
\hline 8 & 20 & 400 & 500 & $80.0 \%$ & 8 & 0 \\
\hline 9 & 47 & 940 & 1000 & $94.0 \%$ & 9 & 16 \\
\hline 10 & 20 & 400 & 400 & $100.0 \%$ & 6 & 0 \\
\hline 11 & 36 & 720 & 1000 & $72.0 \%$ & 8 & 18 \\
\hline 12 & 20 & 400 & 400 & $100.0 \%$ & 7 & 0 \\
\hline 13 & 26 & 520 & 600 & $86.7 \%$ & 6 & 20 \\
\hline 14 & 20 & 400 & 400 & $100.0 \%$ & 7 & 0 \\
\hline 15 & 27 & 540 & 600 & $90.0 \%$ & 10 & 0 \\
\hline 16 & 21 & 420 & & & & \\
\hline
\end{tabular}




\subsection{Scenario 4}

According to Rakhman (2007) in his research said that many earthquakes such as in 2006 at Yogyakarta, Indonesia, have brought the serious houses damages. Reese et al. (2007) was reported that the dominant types of collapsed houses were Non-Permanent and Semi Permanent.

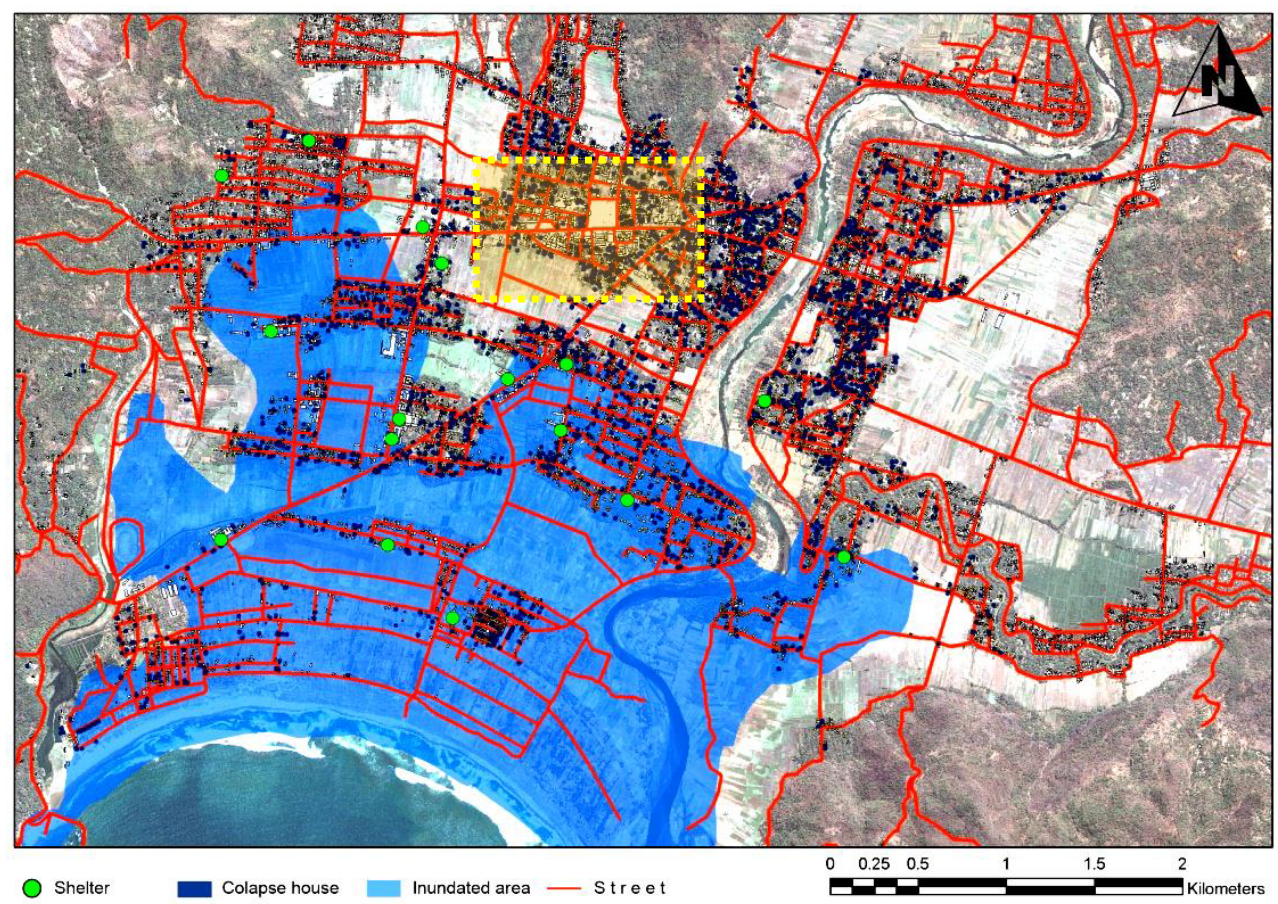

Fig. 9. Blocked network due to building collapse after earthquake and inundated area.

Heavy destruction of houses in a crowded residential area sometimes blocks evacuation networks, and also causes consumption of evacuation time. In agent-based model simulation, agents must follow road network data link from their houses to the evacuation building following the nearest possible path. In scenario-4, several networks were assumed damage due to the collapse of non-permanent houses, and damages of those houses could disturb safety evacuation within limited evacuation time. Fig. 9 shows the inundated areas in the case of suffering network damages.

The zoom in of blocked network is shown in Fig. 10. The number of shelters and agent behavior are same as in Scenario-3. However, in this scenario the agents could not through the damaged road by the collapse of non-permanent housing clusters along them. These conditions were assumed to be an unavailable network due to earthquake, and some agents will be trapped and unable to reach nearest evacuation building.

Fig. 11 shows movement of agent at 2, 7, 10 and 15 minutes. This figure can be seen that some agent cannot reach the evacuation building. In simulation, agents must follow the access road from their houses to the shelter following the nearest path. But in Scenario-4, some agents cannot find the street in front of their houses. About $5 \%$ of the agents trapped in front of a blocked network. In Scenario-4, evacuation time is 21.0 minutes to evacuate more than $95 \%$ agents to the applicable shelters. 


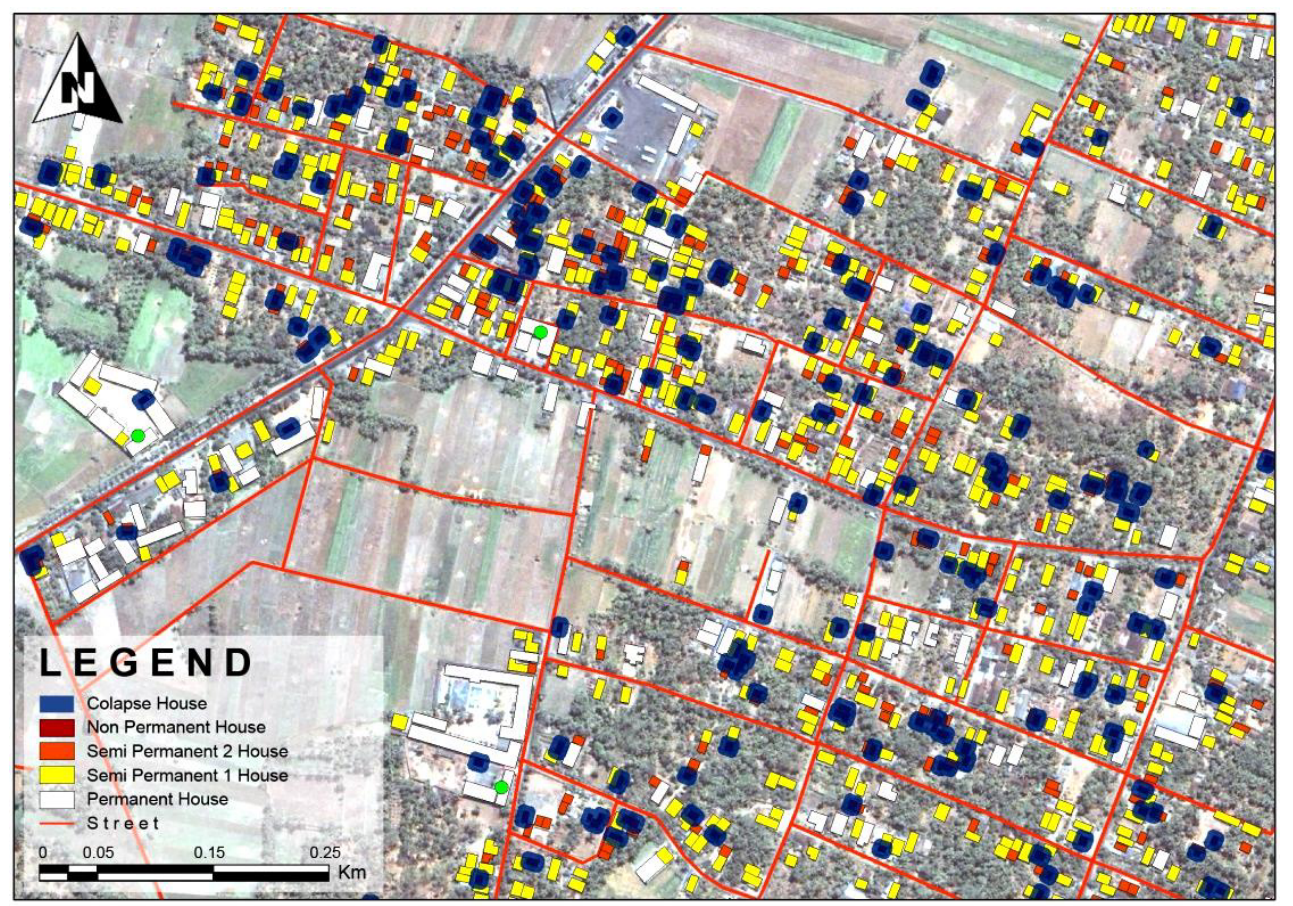

Fig. 10. Zoom in the vulnerable area in central of Pacitan city.
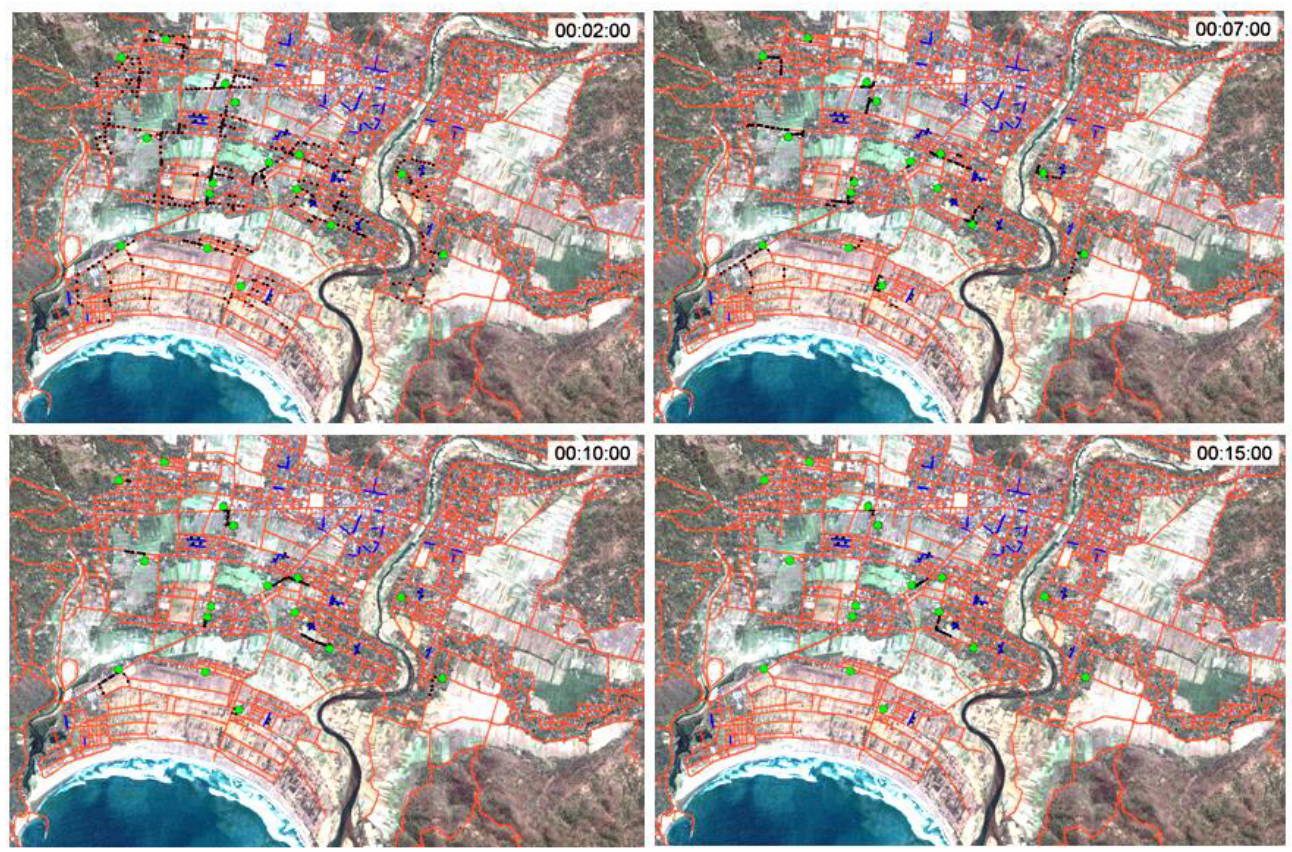

Fig. 11. Movement of agent at 2, 7, 10 and 15 minutes (scenario-4). 


\subsection{Comparison all scenarios}

Figure 12 shows the comparison all of scenarios. Scenario-1 need more time to evacuate all agents to the shelter, Scenario-2 faster and good enough to evacuate the entire agent, but we conducted to add variable of building capacity then evacuate time become longer than before.

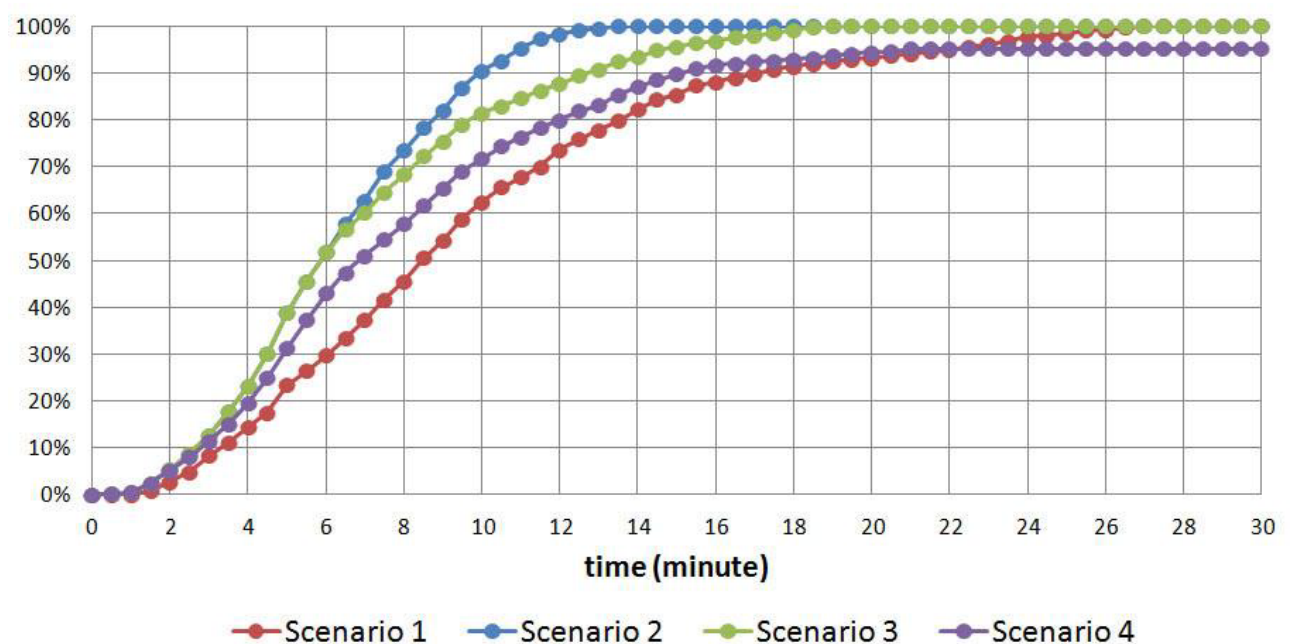

Fig. 12. Comparison all of scenarios.

Table 6 shows the percentage of household that can evacuate to the shelter in every step of evacuation time. This result was found that additional shelters in Scenario-2 provide a significantly result. Compared to the required time for evacuation in Scenario-1, evacuation time was decreased from 27 minutes to 13.5 minutes. That mean, Scenario-2 is 14 minutes faster than Scenario-1. Referring to the tsunami travel time based on the calculation, we estimate tsunami travel time to Pacitan as approximately 21 minutes.

Table 6. Total agents, building capacity and evacuate times.

\begin{tabular}{|c|c|c|c|c|}
\hline Evacuation & Scenario 1 & Scenario 2 & Scenario 3 & Scenario 4 \\
\hline time (minutes) & $\mathbf{( \% )}$ & $\mathbf{( \% )}$ & $\mathbf{( \% )}$ & $\mathbf{( \% )}$ \\
\hline 5.0 & $23.41 \%$ & $38.78 \%$ & $38.78 \%$ & $31.22 \%$ \\
\hline 10.0 & $62.44 \%$ & $90.49 \%$ & $81.46 \%$ & $71.71 \%$ \\
\hline 13.5 & $79.76 \%$ & $100.00 \%$ & $92.44 \%$ & $85.37 \%$ \\
\hline 15.0 & $87.32 \%$ & & $95.61 \%$ & $89.76 \%$ \\
\hline 19.5 & $92.44 \%$ & & $100.00 \%$ & $93.66 \%$ \\
\hline 21.0 & $94.15 \%$ & & & $95.12 \%$ \\
\hline 25.0 & $98.54 \%$ & & & \\
\hline 27.0 & $100.00 \%$ & & & \\
\hline
\end{tabular}

However, it takes additional time to accommodate the evacuation process after the announcement of tsunami warning. Scenario-3 is only 19.5 minutes or less than 21 minutes. Better condition if evacuation time is calculated after the announcement of tsunami warning about 5-7 minutes after the people heard the tsunami warning. In this condition, Scenario-3 is still at the risk of evacuation time.

Evacuation time of scenario-4 is 21.0 minutes. This additional scenario was a scenario after an input variable of unavailable network due to building collapse after the earthquake. 
Some agents need longer evacuation time to the temporal shelter. Around 5\% evacuees trapped at non-permanent residential cluster and cannot reach the nearest shelter.

\subsection{Comparison and similarities}

Based on the results obtained from the previous analysis, in shelter plan analysis and agentbased model simulation, we found that both of analyses have the advantages of each analysis. Shelter plan analysis can provide the result about service area of the shelter based on street database by network analyst extension in ArcGIS. Expected result of this analysis can be obtained to determine the service area every evacuation building. The Agent-Based Model and Simulation (ABMS) is focused to agent, shelter and availability of street, so that the results obtained was different. The Agent-Based Model and Simulation (ABMS) is more accurate in determining the travel time of evacuation, while Shelter Plan Analysis is better in predict the service area of evacuation places. Table 6 shows comparison and similarity between the two analyses. In the Shelter Plan Analysis, distribution of the people is not required. However, in Agent Based-Model and Simulations, data of people distribution is needed as the agent to be simulated.

Table 7. Comparison and similarity of each analysis.

\begin{tabular}{|l|c|c|c|c|c|c|c|}
\hline \multirow{2}{*}{ Analisis } & \multicolumn{4}{|c|}{ Data } & \multicolumn{3}{c|}{ Measurement } \\
\cline { 2 - 9 } & street & shelter & house & people & distance & area & time \\
\hline Shelter Plan & $\checkmark$ & $\checkmark$ & $\checkmark$ & $\times$ & $\checkmark$ & $\checkmark$ & $\times$ \\
\hline Agent-based & $\checkmark$ & $\checkmark$ & $\checkmark$ & $\checkmark$ & $\checkmark$ & $\times$ & $\checkmark$ \\
\hline
\end{tabular}

From the discussion above, we recommend that to design an appropriate strategy related to planning the shelter it would be better if it begins with the Shelter Plan Analysis to determine the service area of each shelter. After analysed with Shelter Plan Analysis, continue the process with Agent-Based Model and Simulation to investigate the time required for evacuation.

With the consideration that evacuation with vehicle sometimes causes a traffic jam, and it could disturb safety evacuation of others, this study only supposes the evacuation by walking under tsunami evacuation. There are no agents ride any vehicles in the simulation, all of agent's speed based on walking speed.

\section{Conclusion}

This study applied both Shelter Plan Analysis and Agent-Based Model Simulation (ABMS) on GIS to establish an applicable strategy for tsunami evacuation plan. In order to set input data for this analysis, we conducted the questionnaire survey in Pacitan city, which is a typical populated coastal city in Indonesia.

From shelter plan analysis, this study revealed that service area of 16 shelters, which allocated on prone residential can serve up to $96 \%$ after upgrading several additional shelters. According to the result of Shelter Plan Analysis, we conducted the service area of current shelter allocation by Network Analyst on GIS. Agent-based model and simulation is used to verify the result of service area based on the speed of evacuation.

Furthermore, limited capacity of evacuation places to the service area was discussed throughout this study. Change of agent behavior in simulation shows that to reach another nearby shelter also requires extended time. These studies said that more additional shelters 
should be allocated in Pacitan to expand the service area even in the case of limited evacuation time. In addition, upgrading the quality of the shelter should be made, especially to upgrade the capacity of building and building strength. Unavoidable variable in the tsunami evacuation model of this study is the different of house quality, where poor quality of houses will block the network, and some agent trapped in that cluster area.

\section{References}

1. A. Muhari, M. Muck., S. Diposaptono, H. Spahn, Sci. Tsunami Haz., 31, 244 (2012)

2. A.T. Crooks, A.J. Heppenstall, Agent-Based Models of Geographical Systems: Introduction to Agent-Based Modelling (Springer Science, London, 2012)

3. S. Balram, S. Dragicevic, Collaborative Geographic Information Systems (Idea Group Inc., New York, 2006)

4. T.J. Cova, P.J. Justin, Transport. Res. A-Pol., 37, 579 (2003)

5. W.M. ElDessouki, Some Developments in Transportation Network Analysis and Design with Application to Emergency Management Problems (Ph.D. Dissertation, North Carolina State University, 1998)

6. J. Rakhman, Jurnal Permukiman, 3, 4 (2008)

7. M.J. North, C.M. Macal, Managing business complexity: discovering strategic solutions with agent-based modeling and simulation (Oxford University Press, 2007)

8. A. Mansourian, A. Rajabifard, M.J. Valadan Zoej, I.P. Williamson, Comput. Geosci., 32, 303 (2006)

9. D. Mardiatno, Tsunami Risk Assessment Using Scenario- Based Approach, Geomorphological Analysis and Geographic Information System, A Case Study in South Coastal Areas of Java Island-Indonesia (Dissertation, Faculty of Geo- and Atmospheric Sciences of the University of Innsbruck, 2008)

10. A. Pal, A.J. Graettinger, M.H. Triche, Emergency evacuation modeling based on geographical information system data (TRB 2003 Annual Meeting, 2003)

11. R. Potangaroa, Proceeding from International Conference on Building Education and Research (BEAR) "Building Resillience” (Auckland, New Zealand, 2008)

12. S.C. Pursals, F.G. Garzon, Eur. J. Oper. Res., 192, 692 (2009)

13. Regional Development Agency of Pacitan, Development planning of the settlement area in Pakistan city 2002-2012 (Final Report, Pemerintah Kabupaten Pacitan, Pacitan, 2002)

14. S. Reese, W.J. Cousins, Nat. Hazards Earth Syst. Sci., 573 (2007)

15. M. Saadatseresht, A. Mansourian, M. Taleai, Eur. J. Oper. Res., 198, 305 (2009)

16. H.D. Sherali, T.B. Carter, A.G. Hobeika, Transport. Res. B-Meth., 25, 439 (1991)

17. S. Sutikno, K. Murakami, A. Suharyanto, Proceedings of the Twentieth International Offshore and Polar Engineering Conference 599 (2010)

18. S. Sutikno, K. Murakami, Proceeding of International Session in Conference on Coastal Engineering, 2, 26 (2011)

19. Y. Tsuji, F. Imamura, H. Matsutomi, C.E. Synolakis, P.T. Nanang, S. Harada, S.S. Han, K.I. Arai, B. Cook, Pure Appl. Geophys., 144, 839 (1995)

20. F. Usman, K. Murakami, Journal of Japan Society of Civil Engineers, 67, 595 (2011)

21. L.Y. Wu, X.S. Zhang, Comput. Oper. Res., 33, 1226 (2006) 